https://doi.org/10.15407/ujpe63.12.1105

V.I. PIPA, A.I. LIPTUGA

V.E. Lashkaryov Institute of Semiconductor Physics, Nat. Acad. of Sci. of Ukraine

(41 Nauky Ave., Kyiv 03028, Ukraine)

\title{
ROTATION OF A THIN HEATED PLATE BY ITS OWN THERMAL RADIATION
}

\begin{abstract}
The results of the theoretical investigation of a heated solid plate rotation caused by its own thermal radiation are presented. The rotational moment of the plate with uniform temperature is due to the asymmetry of a recoil of photons of thermal radiation from different areas of its wide faces. The time dependences of the rotation angle of a rectangular plate with stable temperature and at radiative cooling are calculated. The rotation angle dependences on the plate geometric and optical parameters are studied. It is shown that the rotation angle depends nontrivially on the plate thickness because of the thickness-dependent plate emittance. The numerical calculations are performed for a silicon plate. The biggest rotation effect (rotation angle of $118.5^{\circ}$ for $70 \mathrm{~s}$ ) is obtained for a mirror black plate $0.1 \mathrm{~mm}$ thick at a preset plate temperature of $350 \mathrm{~K}$ and a background temperature of $300 \mathrm{~K}$. The considered model can be useful to develop thermal motors, whose rotors consist of a set of heated plates with photon recoil asymmetry.
\end{abstract}

Keywords: thermal radiation, photon recoil, thin film rotation.

\section{Introduction}

Thermal radiation (TR) emitted by a heated body exerts a mechanical effect on it. Due to the photon recoil, a force (opposite in direction to the TR flux) acts on this body. If the intensities of radiation from various areas of body's surface differ from each other, then moments of forces may act on the body as well. A heated free body may execute a translational, as well as rotational, motion under the photon recoil depending on the TR asymmetry. This effect is inherent to a wide range of objects, from very heavy and bulky (rotation of asteroids by radiation [1], an anomaly in the acceleration of space probes "Pioneer 10 and 11" [2, 3]) to very light and small ones (optically levitating nanoparticles [4], Janus particles [5], Rytov pinwheels [6], etc.). The present work deals with calculating the rotation of a heated solid plate by its own TR.

\section{Results and Discussion}

Let us consider the rotation of a thin rectangular plate heated uniformly to the temperature $T$, while the environment temperature is $T_{1}$. In the $x y z-$ coordinate system, the plate wide faces (edge lengths

(C) V.I. PIPA, A.I. LIPTUGA, 2018

ISSN 2071-0194. Ukr. J. Phys. 2018. Vol. 63, No. 12 $\left.l_{x}, l_{z}\right)$ are located vertically in the planes $x z, y=$ $= \pm l_{y} / 2$. We suppose that $l_{x}, l_{z} \gg l_{y}$ and so consider the radiation pressure on the wide faces only. The plate cross-section, as well as the plate and environmental TR intensities, are sketched in Fig. 1.

To illustrate heat flows, the plate cross-section is presented in the horizontal $x y$-plane coinciding with the figure plane. The rotation $z$-axis is directed perpendicularly to that plane. However, it should be noted that we consider the plate rotation in the horizontal plane around the vertical $z$-axis.

In the presented model, the coefficients of radiation reflection from the different halves of plate wide faces are unequal. For the face $a\left(y=-l_{y} / 2\right)$ on the left $\left(-l_{x} / 2 \leqslant x \leqslant 0\right)$ and right $\left(0 \leqslant x \leqslant l_{x} / 2\right)$ halves, they are $R_{1}$ and $R_{2}$, respectively. The location of such areas on the face $b\left(y=l_{y} / 2\right)$ is opposite to that on the face $a$. As a result, the total intensities of radiation ( $\mathrm{TR}$ from the plate and the reflected background radiation) from the different halves of the wide face are unequal. The pressure exerted by radiation with such an asymmetry leads to the free plate rotation around the $z$-axis. It should be noted that the plate rotation direction depends on the ratios between $R_{1}$ and $R_{2}$, as well as between $T$ and $T_{1}$. 


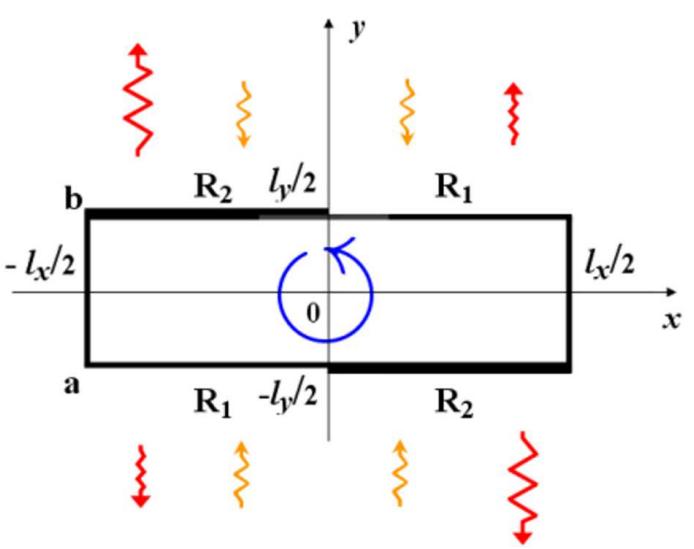

Fig. 1. Diagram (cross-section) of a heated rotating plate. The wide faces $(a)$ and $(b)$ are divided into two halves each that differ in the reflection coefficients $\left(R_{1}\right.$ and $\left.R_{2}\right)$ and TR intensities (arrows of different lengths aimed away from the plate). The arrows directed toward the plate represent the background radiation. The round arrow represents the plate rotation direction around the axis passing through the center of inertia

Let $J(\lambda, \vartheta) d \lambda d \Omega$ designate the density of the normal TR energy flow in the wavelength interval $d \lambda$ into a solid angle element $d \Omega$ at an angle $\vartheta$ to the normal to the plate surface. In accordance with the Kirhhoff's law, $J(\lambda, \vartheta)=A(\lambda, \vartheta) J_{0}(\lambda, \vartheta)$. Here, $A$ is the plate emittance (equal to its absorptance), $J_{0}=4 \pi \hbar c^{2} \lambda^{-5} N \cos \vartheta$, and $N$ is the Planck function.

Let us calculate radiation pressure on the plate right half for $d \lambda=1$ and $d \Omega=1$. TR from that plate part exerts the pressure $A_{1} J_{0}(T) / c$ on the face $b$ (and $A_{2} J_{0}(T) / c$ on the face $a$ ); pressure values of background radiation on these surfaces are $B_{1} J_{0}\left(T_{1}\right) / c$ and $B_{2} J_{0}\left(T_{1}\right) / c$, respectively. Here, $A_{k}=1-R_{k}-D$, $B_{k}=1+R_{k}-D, D$ is the plate transmission coefficient, $k=1,2$. The resulting pressure (a difference between the values of the pressure on the right halves of faces $a$ and $b$ ) is

$P=c^{-1} \iint\left(R_{1}-R_{2}\right)\left(J_{0}(T)-J_{0}\left(T_{1}\right)\right) d \lambda d \Omega$.

The opposite pressure of the same value is applied to the plate left half. If $R_{1}>R_{2}$, then the above pressure is applied to the right half of face $a$ and left half of face $b$ of the heated plate, so it can rotate around the $z$-axis in the direction shown in Fig. 1 .

Let the plate start to rotate at the instant $t=0$. In the cylindrical coordinate system, the plate position is determined by the azimuth angle $\varphi(t)$ that can be found from the equation for angular momentum of the plate

$I_{z} \frac{d^{2} \varphi}{d t^{2}}=K$

with initial conditions $\varphi(0)=0, \quad \dot{\varphi}(0)=0$. Here, $I_{z}=m l_{x}^{2} / 12$ is the plate moment of inertia in the approximation $\left(l_{y} / l_{x}\right)^{2} \ll 1, m$ is the plate mass, $K=P l_{x}^{2} l_{z} / 4$ is the moment of pressure force couple (Eq. (1)). Action of other forces (e.g., friction) is ignored.

We consider two temperature conditions at $t>0$ : 1) the temperature $T(t=0)=T_{0}$ remains constant and 2) the plate temperature decreases due to radiative cooling. The temperature of a heated unfixed plate can be maintained (e.g., by electric current).

By calculating the difference between the radiant energy input and output for the plate, we obtain that, at $t>0, T(t)$ obeys the equation

$\rho l_{y} C_{p} \frac{d T}{d t}=-\iint\left(A_{1}+A_{2}\right)\left(J_{0}(T)-J_{0}\left(T_{1}\right)\right) d \lambda d \Omega$,

where $\rho$ is the plate density, $C_{p}$ is the thermal capacity. Other cooling mechanisms are ignored.

The maximum pressure (Eq. (1)) is achieved, if $R_{1}=1$ and $R_{2}=0$. For such a plate, the transmission coefficient $D=0$; one (mirror) half of each plate face does not emit at all $\left(A_{1}=0\right)$, while another half emits as a blackbody $\left(A_{2}=1\right)$. In this case, we obtain $P=P_{b b}$ from Eq. (1), and the right-hand side of Eq. (3) is $-c P_{b b}$, where

$P_{b b}=\sigma\left(T^{4}-T_{1}^{4}\right) / c$,

and $\sigma$ is the Stefan-Boltzmann constant.

Besides this extreme case, let us consider also the plate (Fig. 1), for which the reflection coefficient $R_{1}=1$, and $R_{2} \equiv R(\lambda, \vartheta)$ is determined by the dielectric properties of a plate material. In this case, $A_{1}=0, A_{2}=1-R$, and the right-hand side of Eq. (3) is expressed in terms of the pressure (Eq. (1)) as $-c P\left(T, T_{1}\right)$.

Let us designate the pressure (Eq. (1)) at $t=0$ as $P_{0}=P\left(T_{0}, T_{1}\right)$. If the initial temperature $T_{0}$ is maintained constant, then Eq. (2) yields

$\varphi=\frac{3 P_{0}}{2 \rho l_{x} I_{y}} t^{2}$.

ISSN 2071-0194. Ukr. J. Phys. 2018. Vol. 63, No. 12 
Let the plate be cooled at $t>0$. For the time interval, in which $T$ decreases but slightly $\left(\left(T_{0}-T\right) / T_{0} \ll\right.$ $\ll 1$ ), Eqs. (1)-(3) yield:

$\varphi=\frac{3 P_{0}}{\gamma^{2} \rho l_{x} l_{y}}\left(e^{-\gamma t}+\gamma t-1\right)$,

where $\gamma$ is determined as

$\gamma=\frac{8 \pi^{2} c^{3} \hbar^{2}}{\rho C_{p} l_{y} k_{\mathrm{B}} T_{0}^{2}} \iint(1-R) N\left(T_{0}\right) \times$

$\times\left(1+N\left(T_{0}\right)\right) \lambda^{-6} \cos \vartheta d \lambda d \Omega$.

For a mirror black plate $\left(R_{1}=1, R_{2}=0\right)$ :

$P_{0}=P_{b b}\left(T_{0}, T_{1}\right), \quad \gamma=4 \sigma T_{0}^{3} /\left(\rho l_{y} C_{p}\right)$

From Eqs. (5) and (6), it follows that the rotation angle does not depend on the plate width $l_{z}$ and increases (as $1 / l_{x}$ ), as the plate length $l_{x}$ decreases. The $\varphi(t)$ dependence on the plate thickness $l_{y}$ is more complicated. Besides the explicit $\varphi(t) \infty 1 / l_{y}$ and $\gamma \infty 1 / l_{y}$ dependences caused by the plate mass, these quantities are also determined by the thickness dependence of the plate emittance.

The time dependences of the plate rotation angle calculated from Eqs. (5) and (6) are presented in Figs. 2 and 3, respectively. In each figure, the curves illustrate the $\varphi(t)$ dependences for silicon plates that have different reflection coefficients and whose thicknesses differ by ten times. The calculations were performed for plates with the length $l_{x}=2 \mathrm{~cm}$, whose thicknesses were considerably over the wavelengths corresponding to the maxima of plate TR spectra and background radiation. This makes it possible to neglect the interference phenomena in the plate TR $[7,8]$. The following parameters were used: the silicon density $\rho=2.32 \mathrm{~g} / \mathrm{cm}^{3}$, thermal capacity $C_{p}=7.56 \times 10^{6} \mathrm{erg} /(\mathrm{g} \cdot \mathrm{K})$, refractive index $n=3.4$, radiation absorption coefficient $\alpha(\lambda) \infty \lambda^{2}$, and $\alpha=15 \mathrm{~cm}^{-1}$ for $\lambda=10 \mu \mathrm{m}$.

Figure 2 presents the $\varphi(t)$ dependence for a uniformly accelerated rotation of the plate $\left(T_{0}(t)=\right.$ $=$ const.). It can be seen from curves 1 and 3 for plates, whose pressure $P_{0}$ does not depend on $l_{y}$, that the rotation angle of a thin plate is over that of a thick one by ten times. For plates with $R_{2} \equiv R(\lambda, \vartheta)$ (curves 2 and 4 in Fig. 2), the pressure $P_{0}$ depends on $l_{y}$; in this case, the ratio between the rotation angles of thin and thick plates is less than ten.

ISSN 2071-0194. Ukr. J. Phys. 2018. Vol. 63, No. 12

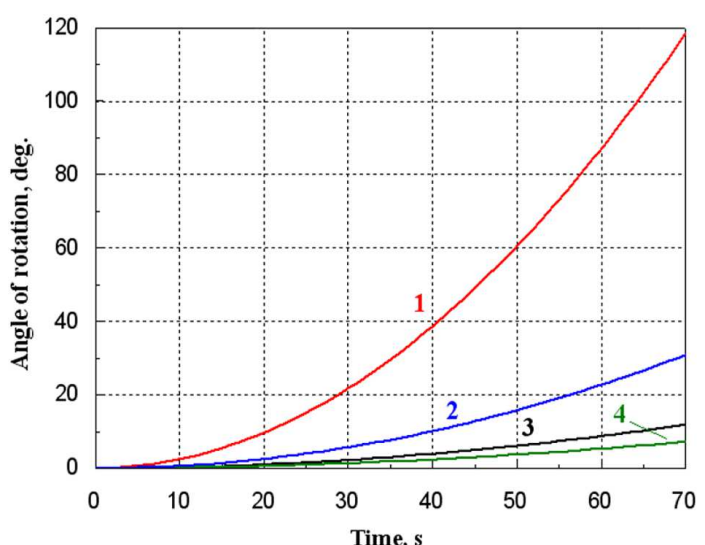

Fig. 2. Time dependence of the silicon plate rotation angle at the constant plate temperature $T=350 \mathrm{~K}$ and background temperature $T_{1}=300 \mathrm{~K}: 1$ and $3-l_{y}=0.1 \mathrm{~mm}$ and $1 \mathrm{~mm}$, respectively, $R_{1}=1, R_{2}=0$; 2 and $4-l_{y}=0.1 \mathrm{~mm}$ and $1 \mathrm{~mm}$, respectively, $R_{1}=1, R_{2}$ is the reflection coefficient of a polished plate

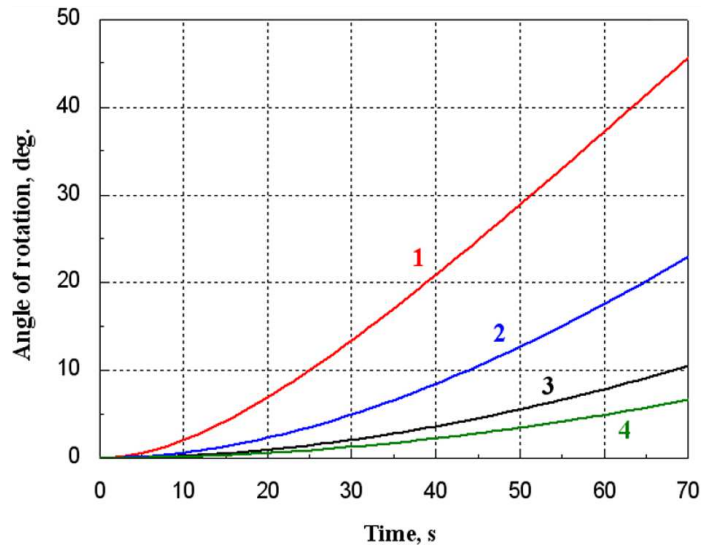

Fig. 3. Time dependences of the silicon plate rotation angle, as the plate temperature decreases. The initial plate temperature $T=350 \mathrm{~K}$, the background temperature $T_{1}$ is constant $\left(T_{1}=300 \mathrm{~K}\right)$. Curves $1-4$ are calculated for the same thicknesses $l_{y}$ and reflection coefficients $R_{1}$ and $R_{2}$ as for the corresponding curves in Fig. 2

Figure 3 shows the $\varphi(t)$ dependences of heated plates, whose temperature decreases because of their radiative cooling. In this case, the rotation angle dependence on the thickness $l_{y}$ is also determined by the radiative cooling rate dependence on $l_{y}$.

By applying the known well-developed technologies of layer deposition onto a polished silicon plate surface, it is rather easy to provide proper conditions (the reflection coefficient close to unity or zero over 
a wide spectral range). One should deposit a metal (or metamaterial) layer in the first case $[9,10]$ or an absorptive layer in the second case $[11,12]$. Layers' thicknesses and, respectively, masses are sufficiently small as compared with those for the considered silicon plate, so they were ignored in our calculations. It should also be noted that the rotation by its own TR can be demonstrated not only by semiconductor plates but by those made of other materials as well.

\section{Conclusions}

We have studied theoretically a possibility to rotate a thin rectangular silicon plate by the photon recoil of its thermal radiation. The rotational moment in a plate with uniform temperature is due to a distinction between the emittances from different plate areas located symmetrically about the rotation axis. The dependence of the rotation angle on geometric, optical, and thermodynamic parameters of a plate is investigated. It is shown that the rotation angle does not depend on the plate width $l_{z}$ and increases proportionally with $1 / l_{x}$, as the plate length $l_{x}$ decreases. The rotation angle depends nontrivially on the plate thickness because of the thickness dependence of the plate emittance. At a preset temperature regime (constant plate temperature of $350 \mathrm{~K}$ and background temperature of $300 \mathrm{~K})$, the biggest effect of rotation $\left(118.5^{\circ}\right.$ for a time of $70 \mathrm{~s}$ ) is obtained for a mirror black plate $0.1 \mathrm{~mm}$ thick. The model considered can be useful for the development of a thermal motor, whose rotor consists of a set of heated plates with a photon recoil asymmetry.

1. M. Kaasalainen, J. Durech, B.D. Warner, Y.N. Krugly, N.M. Gaftonyuk. Acceleration of the rotation of asteroid 1862 Apollo by radiation torques. Nature 446, 420 (2007).

2. V. Toth, S.G. Turyshev. Thermal recoil force, telemetry, and the Pioneer anomaly. Phys. Rev. D 79, 043011 (2009).

3. S.G. Turyshev, V.T. Toth, G. Kinsella, S.C. Lee, S.M. Lok, J. Ellis. Support for the thermal origin of the Pioneer anomaly. Phys. Rev. Lett. 108, 241101 (2012).

4. V. Jain, J. Gieseler, C. Moritz, C. Dellago, R. Quidant, L. Novotny. Direct measurement of photon recoil from a levitated nanoparticle. Phys. Rev. Lett. 116, 243601 (2016).

5. M. Liu, T. Zentgraf, Y. Liu, G. Bartal, X. Zhang. Lightdriven nanoscale plasmonic motors. Nature Nanotechnology 5, 570 (2010).
6. M.T.H. Reid, O.D. Miller, A.G. Polimeridis, A.W. Rodriguez, E.M. Tomlinson, S.G. Johnson. Photon torpedoes and Rytov pinwheels: Integral-equation modeling of non-equilibrium fluctuation-induced forces and torques on nanoparticles. arXiv preprint arXiv:1708.01985 (2017).

7. K.Y. Guga, A.G. Kollyukh, A.I. Liptuga, V.A. Morozhenko, V.I. Pipa. Features of thermal radiation of planeparallel semiconductor wafers. Semiconductors 38, 507 (2004).

8. O.G. Kollyukh, A.I. Liptuga, V. Morozhenko, V.I. Pipa. Effect of the optical characteristics of semiconductor resonator structures on the amplitudes of their thermal radiation lines. Optics Communications 260, 607 (2006).

9. O.S. Heavens. Optical Properties of Thin Solid Films (Dover, 1991).

10. J.-B. Brückner, J. Le Rouzo, L. Escoubas, G. Berginc, O. Calvo-Perez, N. Vukadinovic, F. Flory. Metamaterial filters at optical-infrared frequencies. Optics Express 21, 16992 (2013).

11. J. Lehman, E. Theocharous, G.E.C. Pannell. Gold-black coatings for freestanding pyroelectric detectors. Measurement Science and Technology 14, 916 (2003).

12. I. Mellouki, N. Bennaji, N. Yacoubi. IR characterization of graphite black-coating for cryogenic detectors. Infrared Physics and Technology 50, 58 (2007).

Received 26.07.18

\section{B.I. Пina, A.I. Лinmyza}

\section{ОБЕРТАННЯ ТОНКОЇ НАГРІТОї}

\section{ПЛАСТИНИ ЗА РАХУНОК ВЛАСНОГО}

\section{ТЕПЛОВОГО ВИПРОМІНЮВАННЯ}

$\mathrm{P}$ е $з$ ю м е

Представлено результати теоретичного дослідження обертання твердотільної пластини за рахунок власного теплового випромінювання. Обертальний момент пластини з однорідною температурою зумовлено асиметрією фотонної віддачі теплового випромінювання від різних ділянок ㄲï широких граней. Розраховано часові залежності кута повороту прямокутної пластини в умовах, коли її температура не змінюється, а також в режимі їі радіаційного охолодження. Досліджується залежність кута повороту від геометричних та оптичних параметрів пластини. Показано, що кут повороту нетривіальним чином залежить від товщини пластини через товщинну залежність її випромінювальної здатності. Чисельні розрахунки виконано для кремнієвої пластини. Найбільший ефект обертання (кут повороту $118,5^{\circ}$ за час 70 с) отримано для дзеркально-чорної пластини товщиною 0,1 мм при заданій сталій температурі пластини $350 \mathrm{~K}$ і температурі фону $300 \mathrm{~K}$. Розглянута модель може бути корисною для розроблення теплових двигунів, ротори яких складаються з набору нагрітих пластин з асиметрією фотонної віддачі. 